Submission ID: 43788

\title{
Peculiarities of Azeri-Chirag-Guneshli Field Compartmentalization
}

Y.A. Dyakonova* (Roxar Services AS), D.Sh. Machukaev (Roxar Services AS)

\section{SUMMARY}

The article provides a detailed analysis of the structure and tectonics of the unique Azeri-Chirag-Guneshli oil and gas condensate field based on the integration of 3D seismic and well data. Studies have made it possible to clarify the concept of the formation and development of faults at the Absheron threshold of the South Caspian oil and gas basin. The obtained results indicate the necessity of modeling such deposits as one geological object. 
Специфика блокового строения нефтегазоносных пластов месторождения в Азербайджанском секторе Каспийского моря

Ю.А. Дьяконова*, Д.Ш. Мачукаев (ООО «Роксар Сервисиз»)

\section{Введение}

Представления о структурной геологии нефтегазоносных объектов Кавказкого региона в геолого-гидродинамическом моделировании, как правило, сводятся к построению амплитудных складок, осложненных взбросово-надвиговыми нарушениями, которые разделяют месторождения на гидродинамически изолированные блоки с отличающимися уровнями межфлюидных контактов, а иногда и разным типом насыщения. В последние годы, однако, этой в целом верной и простой концепции стало недостаточно, чтобы описать в модели те новые знания, которые мы получаем благодаря применению новых методик исследований и интерпретации данных. На конкретном примере можно увидеть, как более качественная информация позволяет обнаружить противоречия в модели, найти им геологическое объяснение, и устранить их.

\section{Проблематика вопроса}

Месторождение Азери-Чираг-Гюнешли приурочено к серии вытянутых поднятий, названия которых составляют имя месторождения. Продуктивными являются плиоценовые формации Balakhany, Fasila (Перерыв) и серия пластов pre-Fasila (до-Перерыва). Первые две формации, преимущественно нефтеносные, серия pre-Fasila представлена преимущественно газоносными пластами НКП, ПК и КаС (Рисунок 1).

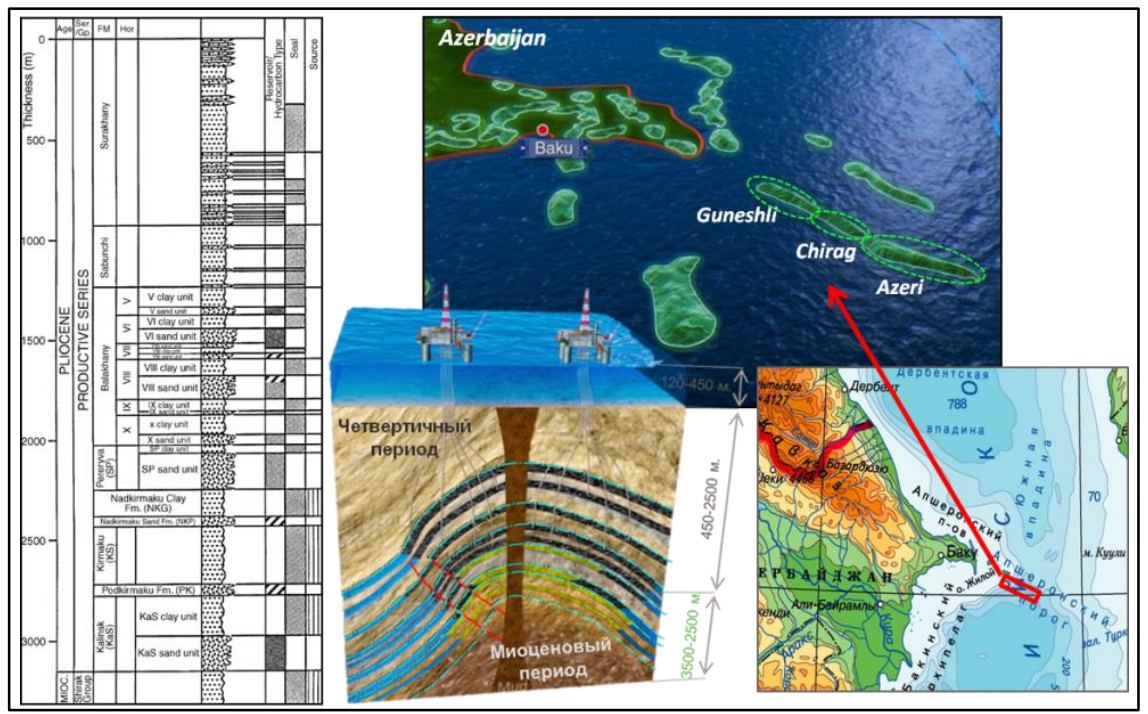

Рисунок 1 Месторождение Азери-Чираг-Гюнешли

До недавнего времени структурная модель представляла собой вытянутую антиклинальную складку осложненную серией продольных и поперечных нарушений, которые разделяли всю площадь на несколько гидродинамически изолированных блоков. Блоковое строение позволяло объяснить различия в положении газонефтяных и водонефтяных контактов, обоснованных испытаниями в скважинах. Противоречия в положениях контактов особенно проявляются при сопоставлении притоков, полученных на противоположных крыльях складок. Например, в пластах NKP и PK на поднятии Гюнешли разница в положении ГНК на северном и южном крыльях превышает 100 м.

Проведенные 3D сейсмические исследования заставили усомниться в принятой концепции. На площади не было обнаружено сугубо поперечных нарушений, а продольные нарушения имели 
ограниченное распространение, что не позволяло полностью гидродинамически разделить северные и южные крылья складок. Ряд промысловых исследований подтвердили сомнения в степени гидродинамической разобщенности площади. В частности, результаты трассерных исследований пласта Перерыв указали на достаточно хорошую связь в межскважинном пространстве [1]. Показательными также стали продолжительные исследования поведения непроводящей зоны в куполе залежи, которая при создании определенного градиента давления становилась проводящей, что было отмечено прямыми измерениями пластового давления [2]. Накопившиеся противоречия потребовали более детальной проработки геологической концепции.

\section{Концепция тектонического строения}

Современная структурно-тектоническая ситуация в Каспийском регионе сформировалась как следствие позднеальпийской коллизии Аравийской и Евразийской плит, продолжающаяся с Олигоценового по настоящее время. На границе Миоцена и Плиоцена в результате резкого нарастания давления с главным вектором юг-север начали формироваться основные зоны поднятий и прогибов Среднего Каспия. Молодая Южно-Каспийская плита, двигаясь под напором Аравийской плиты в северо-восточном направлении, сформировала на границе со Скифско-Туранской плитой Апшероно-Балханский порог, к которому приурочены исследуемые в настоящей работе структурные поднятия [3,4].

Тип тектоничекой деформации и её вектор определили вытянутую форму структурных элементов и их преимущественно юго-восточно-северо-западную ориентацию. Дизъюнктивные нарушения представлены взбросово-надвиговыми нарушениями, ориентированными перпендикулярно направлению максимального сжатия, т.е. субпараллельно осям структурных поднятий.

\section{Особенности строения складок и разломов}

Изучение сейсмических разрезов на площади АЧГ позволило дополнить концепцию структурно-тектонического строения площади следующими деталями:

- Изучаемые складки можно считать результатом тангенциально-продольного смятия [5], которое подразумевает концентрацию напряжений в осевой зоне структуры. При этом, вектор напряжения может быть разнонаправленным в нижней и верхней частях разреза. На рисунке 2 можно увидеть, что в интервале залегания серии Pereriv и ниже пласты подвергались сжатию, что привело к образованию амплитудных надвиговых нарушений. В то же время, в верхней части разреза отмечаются сбросовые нарушения, что является признаком напряжений растяжения. Характерной для данного типа смятия также является вариация толщин отложений - в верхней части разреза толщина стратиграфических интервалов возрастает на крыльях складки, а в нижней части в своде.

- Важной особенностью является наличие зоны множественных дислокаций пород в ядре структуры, где в складках подобного рода отмечаются максимальные напряжения (Рисунок 3). Данная зона совпадает с осевой плоскостью складки и прослеживается вдоль всего комплекса поднятий АЧГ в интервале залегания пластов pre-Fasila. Множественные локальные нарушения сплошности пород, иногда формирующие дуплексные системы [6], а также возможные катакластичекие процессы, характерные для зон больших напряжений [7], могли сформировать здесь непроницаемый или слабо проницаемый барьер для фильтрации флюидов, который может служить объяснением различия в положении межфлюидных контактов на северном и южном крыльях складки. 


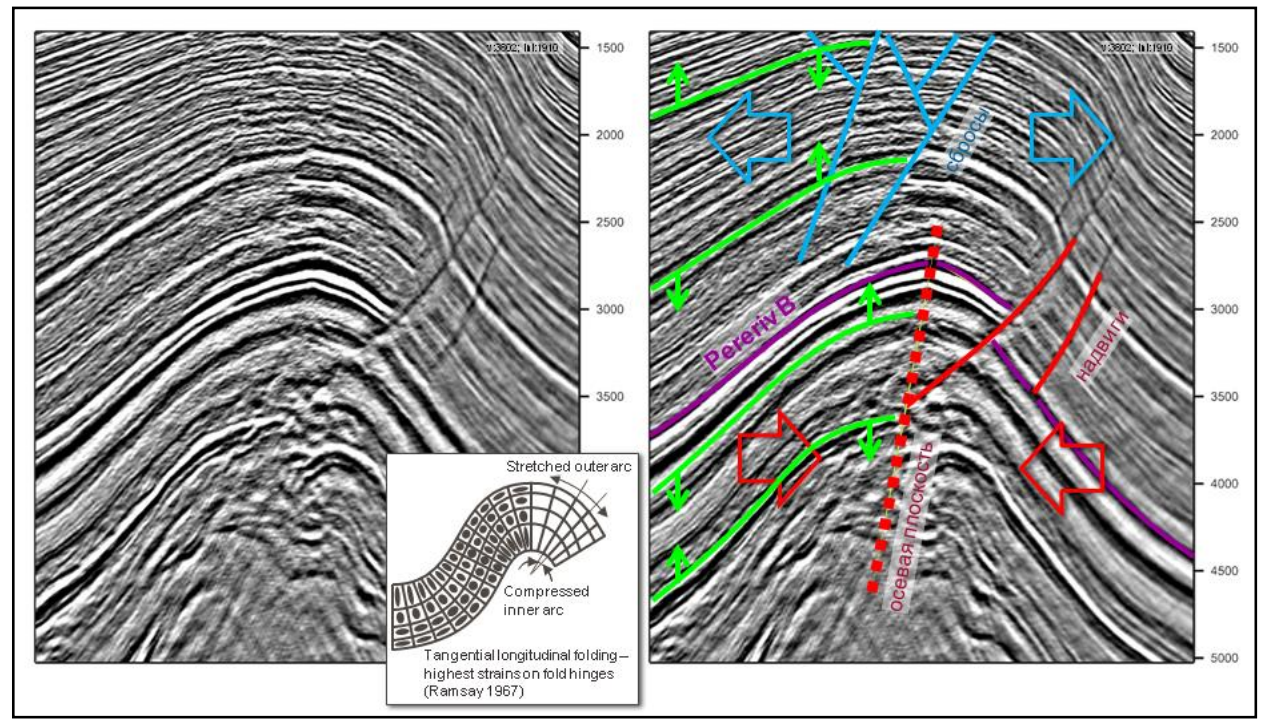

Рисунок 2 Системы разломов

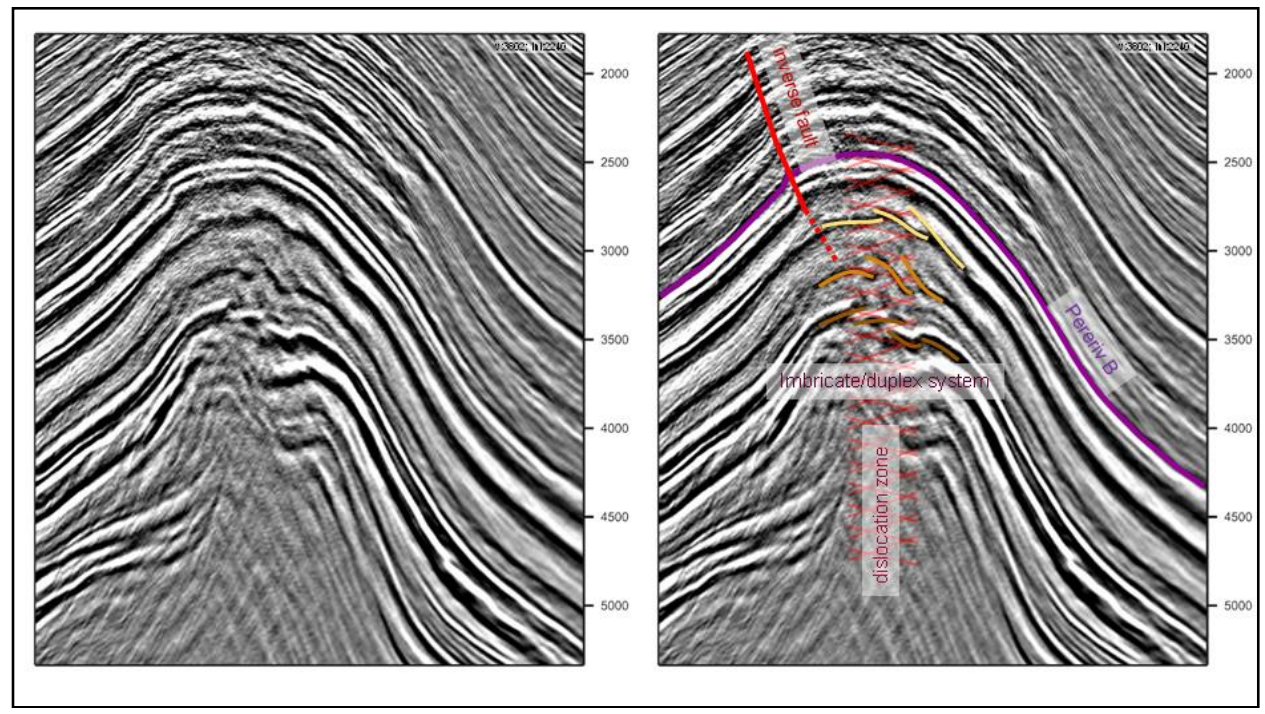

Рисунок 3 Осевая зона множественных дислокаций пород

- Bce отмечаемые на площади проявления грязевого вулканизма связаны с осевыми зонами дислокаций и вносят свой вклад в гидродинамическое разобщение крыльев складок.

- Высокоамплитудные взбросово-надвиговые нарушения, встречающиеся на крыльях структур, ориентированы преимущественно параллельно осям складок. Но на стыке структурных элементов, как например, в зоне сочленения поднятий Чираг и Азери (Рисунок 4), плоскости разрывных нарушений могут загибаться в направлении оси складки, упираясь в осевую зону дислокаций или связанные с ней грязевые вулканы. Это приводит к ухудшению сообщаемости между поднятиями, но не изолирует их полностью.

- Взбросово-надвиговые нарушения, как правило, представлены двумя и более параллельными разломами со смещенными относительно друг друга максимумами амплитуд. Подобное строение допускает возможность фильтрации флюидов через трансферную зону даже при значительной суммарной амплитуде системы разломов [8]. 


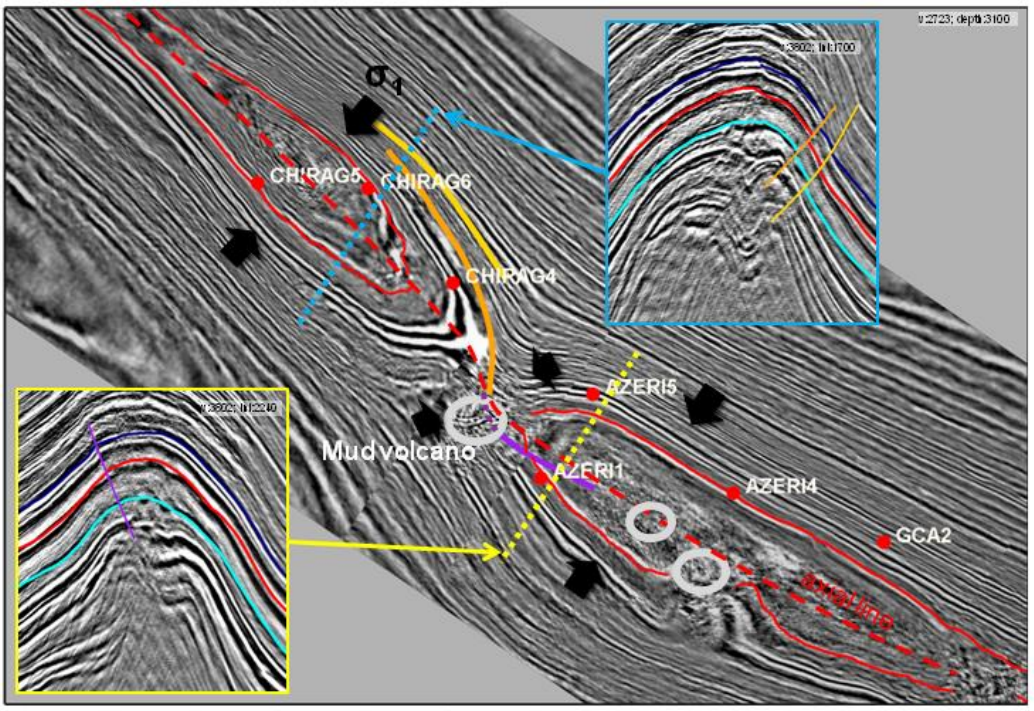

Рисунок 4 Зона сочленения поднятий Чираг и Азери

Перечисленные структурные особенности позволяют предположить, что наличие зон высокоамплитудных дизъюнктивных нарушений не гарантируют отсутствие фильтрации флюидов через эти зоны, так же как отсутствие явных признаков амплитудных дислокаций на сейсмических разрезах не гарантирует отсутствие гидродинамических барьеров или зон ухудшенной фильтрации.

\section{Выводы}

Уточнение геологического строения складок позволило разрешить накопившиеся в геологогидродинамической модели противоречия, введя в концептуальную модель понятие зон множественных дислокаций породы. Эти зоны развиваются вдоль осевой плоскости в ядрах антиклинальных складок, сформировавшихся в результате продольно-тангенциального смятия. С гидродинамической точки зрения эти зоны могут служить условными фильтрационными барьерами, которые в начальном состоянии залежи могут обеспечивать изоляцию блоков с разными уровнями межфлюидных контактов, однако в процессе разработки, при достижении определенного градиента давления, становятся проницаемыми. На практике такие зоны моделируются как субвертикальные разломы без смещения, проводимость которых зависит от перепада давления между блоками.

Особенности строения высокоамплитудных надвиговых нарушений на подобных объектах говорят о возможность перетоков флюидов между крупными структурными элементами, каковыми в нашем случае являются поднятия Азери, Чираг, Гюнешли, и указывают на необходимость их моделирования как единого геолого-гидродинамического объекта.

\section{Благодарности}

Авторы выражают благодарность компании SOCAR за возможность опубликовать полученные результаты.

\section{Библиография}

1. N. Kuramshina, T. Ibrahimov Surveillance helps to get a better understanding of reservoir connectivity in Azeri part of ACG [2015] SPE Annual Caspian Technical Conference \& Exhibition SPE-177328, Baku

2. T. Ibrahimov History of history match in Azeri field [2015] SPE Annual Caspian Technical Conference \& Exhibition SPE-177395, Baku 
3. A.A.Narimanov, The petroleum systems of the South Caspian Basin. Basin Modelling: Advances and Applications edited by A. G. Doré at al. [1993] NPF Special Publication 3, 599-608, Elsevier, Amsterdam. Norwegian Petroleum Society (NPF)

4. И.С.Гулиев, Д.Л.Федоров, С.И.Кулаков [2009] Нефтегазоносность Каспийского региона. Баку, Nafta-Press

5. J.G.Ramsay [1967] Folding and Fracturing of Rocks

6. S.E.Boyer \& D.Elliott [1982] Thrust systems. Bull.Am.Ass.Petrol.Geol. 66, 1196-1230

7. B.R.Crawford [1998] Experimental fault sealing: shear band permeability dependency on cataclastic fault gouge characteristics, in Structural Geology in Reservoir Characterization, edited by M. P. Coward, S. Daltaban, and H. Johnson, Geol. Soc. Spec. Publ. 127, 27-47

8. C.Childs, J.Watterson, J.J.Walsh [1996] A model for the structure and development of fault zones, Journal of the Geological Society, London, 153, 337-340

\section{References}

1. N. Kuramshina, T. Ibrahimov Surveillance helps to get a better understanding of reservoir connectivity in Azeri part of ACG [2015] SPE Annual Caspian Technical Conference \& Exhibition SPE-177328, Baku

2. T. Ibrahimov History of history match in Azeri field [2015] SPE Annual Caspian Technical Conference \& Exhibition SPE-177395, Baku

3. A.A.Narimanov, The petroleum systems of the South Caspian Basin. Basin Modelling: Advances and Applications edited by A. G. Doré at al. [1993] NPF Special Publication 3, 599-608, Elsevier, Amsterdam. Norwegian Petroleum Society (NPF)

4. I.S.Guliev, D.L.Fedorov, S.I.Kulakov [2009] Oil and gas potential of the Caspian region. Baku, Nafta-Press

5. J.G.Ramsay [1967] Folding and Fracturing of Rocks

6. S.E.Boyer \& D.Elliott [1982] Thrust systems. Bull.Am.Ass.Petrol.Geol. 66, 1196-1230

7. B.R.Crawford [1998] Experimental fault sealing: shear band permeability dependency on cataclastic fault gouge characteristics, in Structural Geology in Reservoir Characterization, edited by M. P. Coward, S. Daltaban, and H. Johnson, Geol. Soc. Spec. Publ. 127, 27-47

8. C.Childs, J.Watterson, J.J.Walsh [1996] A model for the structure and development of fault zones, Journal of the Geological Society, London, 153, 337-340 